\title{
PENERAPAN METODE ELECTRE II DALAM MENCARI FAKTOR HAMBATAN SISWA SULIT BERKONSENTRASI DALAM MATA PELAJARAN
}

\author{
Nirwanda Desnila Putri ${ }^{1}$, Poningsih ${ }^{2}, \operatorname{Irawan}^{3}$ \\ ${ }^{1}$ Mahasiswa Program Studi Sistem Informasi STIKOM Tunas Bangsa Pematang Siantar \\ ${ }^{2,3}$ AMIK Tunas Bangsa Pematangsiantar, Indonesia \\ Email: ${ }^{1}$ nirwandadesnila001@gmail.com, ${ }^{2}$ poningsih@amiktunasbangsa.ac.id, ${ }^{3}$ irawaniwan56@ gmail.com
}

\begin{abstract}
Abstrak
Pendidikan merupakan upaya khusus pemerintah untuk menyediakan generasi dengan potensi akademis yang tepat dimana penerus mencapai kemampuan yang diperlukan untuk bertahan hidup dalam berbangsa-bangsa. Proses pengambilan data dilakukan di sekolah. Tapi tetap daja, semuanya tidak berjalan semulus yang diharapkan. Tujuan dari penelitian ini adalah untuk mengidentifikasi masalah yang menjadi faktor hambatan yang mempengaruhi siswa untuk mencapai tjuan pembelajaran. Untuk solusi, penulis menyarankan penggunaan algoritma ELECTRE II sebagai perhitungan, dan VB NET 2010 untuk pengaplikasiannya. Hasil yang diperoleh adalah A03 sebagai alternatif tebaik dengan rata-rata terbesar adalah teman.
\end{abstract}

Kata kunci: Sistem Pendukung Keputusan, Electre II, Vb Net, Konsentrasi,Siswa

\begin{abstract}
Education is an effort specifically by goverments to provide the generation with appropriate academic potentials through which the successors attain the required capabilities to survive the natiions. The process this transfer of information is carried out in school. But still, every thing does not run as smoothly as expected. The purpose of this research is to identify the problems serving as barrcades affecting the students to achieve the goals of learning.For a solution, the writer suggests the use of algorithm ELECTRE II as calculation to discover the best alternative. This method is implemented into an application of Vb Net 2010. The result obtined is A03 having best alternative while the biggest average is friend.
\end{abstract}

Keywords: Decision Support System, Electre ii, Vb Net, Concentration, Students.

\section{PENDAhULUAN}

Dalam setiap tahapan kelas belajar tidak sedikit siswa yang mulai merasakan kejenuhan dalam belajar apalagi pada tingkat SMA. Baik itu dikarenakan pelajaran yang tidak disukai, banyaknya tugas yang diberikan, guru yang mengajar, perhatian orang tua, maupun dikarenakan pergaulan. Sedangkan setiap siswa dituntut untuk mengikuti setiap mata pelajaran yang diberikan, dengan sanksi bila tidak memenuhi nilai ketentuan maka siswa tersebut akan ditinggal kelaskan. Seperti yang terjadi pada MAs Al-Washliyah 26 Tinokkah merupakan Pimpinan Ranting yang berada di Desa Tinokkah, Kec. Sipispis, Kab. Serdang Bedagai, Sumatera Utara.

Sekolah ini memiliki 2(dua) tingkat pendidikan SMP dan MTs, dan MA. Banyaknya mata pelajaran yang harus diikuti oleh setiap siswanya membuat siswa tersebut terkadang jenuh dan tidak memperhatikan pelajaran yang diberikan oleh tenaga pengajar. Tidak sedikit juga siswa yang merasa kurang merasa puas dengan pengajaran guru, seperti menyepelekan, bahkan tidak menghargai guru. Pengaruh teman sebangku juga dapat mempengaruhi konsentrasi belajar seseorang, dimulai dengan mengajak bicara, bercanda, dan terkadang terlalu menyepelekan pelajaran. Terkadang peranan orang tua yang perhatian akan kegiatan belajar siswa juga mempengaruhi perkembangan belajar juga mental seorang anak. Jika orang tua selalu menanyakan bagaimana perkembangan anak selama disekolah maka anak tersebut akan merasa diperhatikan. Banyak siswa yang mencari perhatian disekolah dengan cara yang buruk alasan utamanya dikarenakan anak tersebut kurang diperhatikan oleh orang tuanya sendiri.

Untuk menentukan faktor hambatan siswa sulit berkonsentrasi dalam mata pelajaran penulis akan membahas apa saja yang mempengaruhi siswa tersebut dalam memahami mata pelajaran yang diberikan. Penelitian ini menggunakan metode Electre II untuk dapat membantu mencari faktor hambatan siswa tersebut sulit berkonsentrasi dalam mata pelajarannya. Metode Electre sebagai salah satu metode $M A D M$ secara luas diakui mempunyai performa yang baik untuk menganalisis kebijakan yang melibatkan kriteria kualitatif dan kuantitatif[1]. Metode ELECTRE ini dapat digunakan pada kondisi dimana alternatif yang kurang sesuai dengan kriteria dieliminasi dan alternatif yang sesuai dapat dihasilkan[2].Electre II digunakan untuk melakukan perangkingan, dan juga bobot dapat dicari dengan menggunakan metode Electre II itu sendiri. Dari hasil yang diperoleh diharapkan dapat membantu guru untuk mengetahui apa penyebab dari siswa sulit berkonsentrasi dalam belajar mereka sehingga dapat membantu kelangsungan belajar yang aktif antara siswa dan guru dan meningkatkan pembelajaran agar tidak ada lagi siswa yang mendapat nilai buruk dan harus melakukan ujian ulang (remedial).

\section{TEORITIS}

\subsection{Sistem Pendukung Keputusan}

Sistem Pendukung Keputusan (SPK) atau Decision Support System (DSS) adalah sebuah sistem yang mampu memberikan kemampuan pemecahan masalah maupun kemampuan pengkomunikasian untuk masalah dengan kondisi semi terstruktur dan tak terstruktur. Sistem ini digunakan untuk membantu pengambilan keputusan dalam situasi semi 
terstruktur dan situasi yang tidak terstruktur, dimana tak seorangpun tahu secara pasti bagaimana keputusan seharusnya dibuat[3][4].

Sistem pendukung keputusan (SPK)adalah sebuah sistem yang dimaksudkan untuk mendukung para pengambil keputusan dalam keputusan semi terstruktur. SPK dimaksudkan untuk menjadi alat bantu bagi para pengambil keputusan untuk memperluas kapabilitas mereka namun tidak menggantikan penilaian mereka[5][6].

\subsection{Algoritma Elimination Et Choix Traduisant La Realite (ELECTRE II)}

Metode Electre telah berkembang melalui sejumlah versi (I, II, III, IV, 1S). Semua versi didasarkan pada konsep dasar yang sama namun secara operasional berbeda. Metode Electre I didesain untuk melakukan pemilihan, sedangkan Electre ii digunakan untuk perangkingan. Kedua versi ini menggunakan tipe kriteria yang sederhana,dalam arti nilai treshold-nya sama untuk semua kriteria sedangkan versi lain menggunakan pseudo kriteria yang nilai treshold nya tidak sama untuk semua kriteria[1].

Metode ELECTRE sebagai salah satu metode MADM secara luas diakui mempunyai performa yang baik untuk menganalisis kebijakan yang melibatkan kriteria kualitatif dan kuantitatif.

Tahap-tahap metode Electre dapat dilihat seperti dibawah ini: [1].

1. Tujuan normalisasi adalah untuk mendapatkan nilai berdimensi dengan kriteria yang berbeda agar keduanya dapat dibandingkan satu sama lain. Dalam prosedur ini, setiap atribut diubah menjadi nilai yang comparable. Setiap normalisasi dari nilai rij dapat dilakukan dengan Rumus :

$$
r i j=\frac{X_{i_{j}}}{\sum_{i=1}^{m} X_{i_{j}}^{2}}
$$

2. Pembobotan pada matrik yang telah dinormalisasi. Setelah di normalisasi, setiap kolom dari matrik R dikalikan dengan bobot-bobot (wj) yang ditentukan oleh pembuat keputusan. Sehingga, weighted normalized matrix adalah $\mathrm{V}=\mathrm{RW}$ yang ditulis dala rumus ini :

$R_{w}=\left[\begin{array}{cccc}\text { W1R11 } & \text { W1R12 } & \ldots & \text { WnR1n } \\ \text { W2R21 } & \text { W2R22 } & \ldots & \text { WnR2n } \\ \ldots & \ldots & \ldots & \text { WnRmn }\end{array}\right]$

3. Menentukan Concordance dan Discordance set. Untuk mencari nilai Concordance adalah:

Ckl $=\{\mathrm{j}, \mathrm{ykj} \geq \mathrm{yij}\}$, untuk $\mathrm{j}=1,2,3, \ldots, \mathrm{n}$;

sebaliknya untuk mencari nilai Discordance adalah :

$\operatorname{Dkl}=\{\mathrm{j}, \mathrm{ykj}<y \mathrm{ij}\}$, untuk $\mathrm{j}=1,2,3, \ldots, \mathrm{n}$;

4. Hitung matriks Concordancedan Discordance.

a. Concordance, Untuk menentukan nilai dari elemen-elemen pada matriks Concordance adalah dengan menjumlahkan bobot-bobot yang termasuk dalam subset Concordance, secara matematisnya adalah pada Rumus:

$C k l=\sum j c w W j$

b. Discordance, Untuk menentukan nilai dari elemenelemen pada matriks Discordance adalah dengan membagi maksimum selisih nilai kriteria yang termasuk dalam subsetDiscordance dengan maksimum selisih nilai seluruh kriteria yang ada, secara matematisnya adalah :

$$
D_{k l}=\frac{\{\max (v m n-v m n-1 n)\} ; m, n \in D k l}{\{\max (v m n-v m n-1 n)\} ; m, n \quad=1,2,3}
$$

5. Menentukan matrik dominan Concordancedan Discordance.

a. Concordance, Matrik dominan Concordance dapat dibangun dengan bantuan nilai threshold, yaitu dengan membandingkan setiap nilai elemen matriks Concordance dengan nilai threshold C'.

$C k l \geq C^{\prime}$

Dengan nilai treshold c adalah

$C^{\prime}=\frac{\sum n k=1 \sum n i=1}{\operatorname{Cklm} *(\mathrm{~m}-1)}$

Dan nilai setiap elemen matriks $f$ sebagai matriks dominan Concordance ditentukan sebagai berikut :

$F_{k l}=1$, jika $c_{k l} \geq c^{\prime}$ dan $f_{k l}=0$, jika $c_{k l}<c^{\prime}$

b. Discordance, Untuk membangun matriks dominan Discordance juga menggunakan bantuan nilai threshold d' yaitu :

$D^{\prime}=\frac{\sum \mathrm{n} \mathrm{k}=1 \sum \mathrm{n} \mathrm{i}=1 \mathrm{Dkl}}{\mathrm{m} *(\mathrm{~m}-1)}$

Dan nilai setiap elemen untuk matriks g sebagai matriks dominan Discordance ditentukan sebagai berikut:

$G_{k l}=0$, jika $D_{k l} \geq D^{\prime}$ dan $G_{k l}=1$, jika $D_{k l}<D^{\prime}$

6. Menentukan Concordance murni dan Discordance murni.

a. Concordance murni, dicari dengan mengurangkan nilai perbaris dengan kolom dari matriks Concordance yang mana masing-masing baris dan kolom dijumlahkan. Rumus mencarinya sebagai berikut: 


$$
J_{j}=\sum n k=1 c(j, k)-\sum n k=1 C(k, j),(j \neq k)
$$

b. Discordancemurni, dicari dengan mengurangkan nilai perbaris dengan kolom dari matriks Discordance yang mana masing-masing baris dan kolom dijumlahkan. Rumus mencarinya sebagai berikut:

$$
D_{j}=\sum n k=1 d(j, k)-\sum n k=1 d(k, j),(j \neq k)
$$

Setelah kedua indeks ini diperkirakan, dua peringkat diperoleh berdasarkan dua indeks ini dan peringkat rata-rata ditentukan dari dua peringkat ini. Berdasarkan rangking rata-rata, maka alternative tersebut dipilih yang memiliki rangking rata-rata terbaik.

\section{ANALISA DAN PAMBAHASAN}

\subsection{Tahap Pengumpulan Data}

Data yang digunakan menggunakan jenis statistik inferensial. Statistik inferensial adalah statistik yang berkaitan dengan analisis data (sampel), kemudian diambil kesimpulan yang digeneralisasikan kepada seluruh populasi dan digunakan untuk menarik inferensi dari sampel ke populasi. Pada penelitian ini data diperoleh dari Kuesioner dengan memberikan sebuah pertanyaan atau pernyataan kepada siswa-siswi Madrasah Aliyah Al - Washliyah 26 Desa Tinokkah. Kuesioner yang digunakan dalam penelitian ini dapat dilihat pada gambar 1.

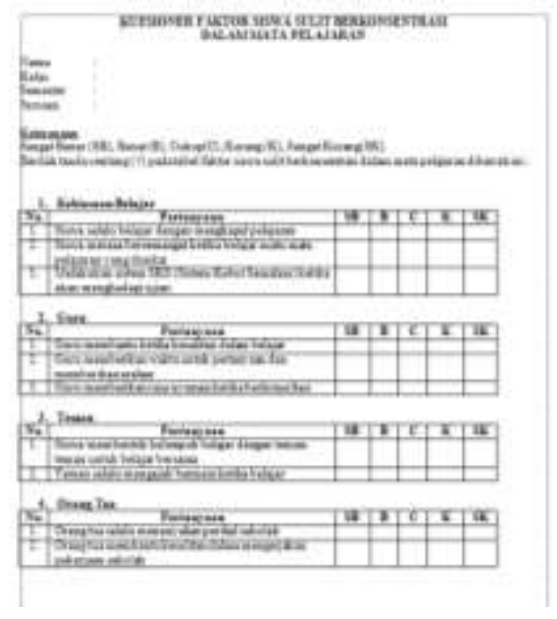

Gambar 1. Kuesioner

Dalam penelitian, data yang digunakan akan diolah dari hasil kuesioner yang diberikan kepada siswa-siswa MA Al- Jam'iyatul Washliyah 26 Tinokkah kelas 12 (3). Kriteria yang digunakan dalam kuesioner yaitu:

1. Kebiasaan belajar

2. Guru

3. Teman

4. Orang Tua

Kriteria terdiri dari pertanyaan yang diajukan ke siswa yang diberikan. Kuesioner yang telah dilakukan selanjutnya mencari perengkingan dari kriteria yang digunakan. Setiap kriteria terdiri dari 2 atau lebih pertanyaan yang diajukan ke siswa yang diberikan dengan menggunakan skalalinker 5 yang terdiri dari SB (Sangat Benar), B (Benar), C (Cukup), K (Kurang), dan SK (Sangat Kurang). Kemudian data diolah menggunakan metode Electre II dan akan di buat dengan mengunakan aplikasi VB NET.

\subsection{Perhitungan Metode Electre II}

Untuk mendapatkan hasil dari penelitian yang dilakukan, berikut uraian perhitungan manual yang akan di jelaskan. Berikut data yang diperoleh dalam penelitian ini dapat dilihat pada tabel 1.

Alternatif yang di gunakan ada 4 alternatif dan 20 kriteria yaitu :

1. Kebiasaan Belajar

2. Guru

3. Teman

4. Orang Tua

Tabel 1. Data Alternatif

\begin{tabular}{ccccc}
\hline \multirow{2}{*}{ Kriteria } & \multicolumn{4}{c}{ Alternatif } \\
& Kebiasaan Belajar & Guru & Teman & Orang Tua \\
\hline C1 & 4,67 & 4,33 & 3,5 & 4,5 \\
C2 & 3,67 & 3 & 5 & 1 \\
C3 & 3,67 & 3,67 & 5 & 2
\end{tabular}




\begin{tabular}{lcccc} 
C4 & 4,33 & 4 & 3 & 2 \\
C5 & 3 & 4 & 3 & 3 \\
C6 & 4,67 & 3 & 4,5 & 3 \\
C7 & 4,67 & 3,67 & 4,5 & 1,5 \\
C8 & 3,67 & 4,67 & 3,5 & 2 \\
C9 & 4 & 4 & 4,5 & 3 \\
C10 & 3 & 3,33 & 4 & 1 \\
C11 & 3,33 & 4,67 & 4 & 4 \\
C12 & 3,67 & 4 & 4 & 3 \\
C13 & 4 & 3,67 & 5 & 3 \\
C14 & 4,67 & 3 & 4 & 3 \\
C15 & 3,33 & 3,67 & 3 & 3,5 \\
C16 & 4,67 & 4 & 4,5 & 3,5 \\
C17 & 4,33 & 4 & 3,5 & 3,5 \\
C18 & 4,67 & 3 & 4,5 & 3 \\
C19 & 3,33 & 3,67 & 3,5 & 4,5 \\
C20 & 3,67 & 3 & 3,5 & 3 \\
\hline
\end{tabular}

a. Normalisasi matrik keputusan dapat dilakukan dengan persamaan(1) :

$$
\begin{aligned}
& X_{1} \\
& =\sqrt{(4,67)^{2}+(4,33)^{2}+(3,5)^{2}+(4,50)^{2}} \\
& =8,5473 \\
& r_{11}=\frac{4,67}{8,5473}=0,5460 \\
& r_{21}=\frac{4,33}{8,5473}=0,5069 \\
& r_{31}=\frac{3,5}{8,5473}=0,4095 \\
& r_{41}=\frac{3}{8,5473}=0,5265
\end{aligned}
$$

Perhitungan diatas merupakan nilai normalisasi dari kriteria $\mathrm{C} 1$, untuk C2 hingga C20 menggunakan cara yang sama dengan menggunakna persamaan(1) hingga diperoleh hasil normalisasi sebagai berikut:

Tabel 2. Normalisasi Nilai Matriks

\begin{tabular}{ccccc}
\hline \multirow{2}{*}{ Kriteria } & \multicolumn{4}{c}{ Alternatif } \\
& Kebiasaan Belajar & Guru & Teman & Orang Tua \\
\hline C1 & 0,546 & 0,5069 & 0,4095 & 0,5265 \\
C2 & 0,5268 & 0,431 & 0,7184 & 0,1437 \\
C3 & 0,4905 & 0,4905 & 0,6688 & 0,2675 \\
C4 & 0,6269 & 0,5787 & 0,434 & 0,2894 \\
C5 & 0,4575 & 0,61 & 0,4575 & 0,4575 \\
C6 & 0,6024 & 0,3872 & 0,5808 & 0,3872 \\
C7 & 0,6143 & 0,4826 & 0,5923 & 0,1974 \\
C8 & 0,5111 & 0,6505 & 0,4878 & 0,2788 \\
C9 & 0,5111 & 0,5111 & 0,575 & 0,3833 \\
C10 & 0,4925 & 0,5471 & 0,6566 & 0,1642 \\
C11 & 0,4138 & 0,5794 & 0,4966 & 0,4966 \\
C12 & 0,4949 & 0,5421 & 0,5421 & 0,4066 \\
C13 & 0,5022 & 0,4604 & 0,6277 & 0,3766 \\
C14 & 0,6244 & 0,4017 & 0,5356 & 0,4017 \\
C15 & 0,4925 & 0,5418 & 0,4433 & 0,5171 \\
C16 & 0,5567 & 0,4771 & 0,5368 & 0,4175 \\
C17 & 0,5628 & 0,5195 & 0,4546 & 0,4546 \\
C18 & 0,6024 & 0,3872 & 0,5808 & 0,3872 \\
C19 & 0,4413 & 0,4855 & 0,4634 & 0,5957 \\
C20 & 0,5547 & 0,4538 & 0,5295 & 0,4538 \\
\hline
\end{tabular}

b. Pembobotan pada matriks yang telah dinormalisasi Matriks V merupakan hasil perkalian R dengan W(bobot), dimana w(bobot) dapat dilihat pada tabel 3.

Tabel 3. Matriks Setelah Dinormalisasikan $\left(\mathrm{R}^{*} \mathrm{w}\right)$

Kriteria Alternatif




\begin{tabular}{lcccc} 
& Kebiasaan Belajar & Guru & Teman & Orang Tua \\
\hline C1 & 0,0519 & 0,0482 & 0,0389 & 0,05 \\
C2 & 0,0474 & 0,0388 & 0,0647 & 0,0129 \\
C3 & 0,0422 & 0,0422 & 0,0573 & 0,023 \\
C4 & 0,0508 & 0,0469 & 0,0351 & 0,0234 \\
C5 & 0,0349 & 0,0465 & 0,0349 & 0,0349 \\
C6 & 0,0428 & 0,0275 & 0,0412 & 0,0275 \\
C7 & 0,0409 & 0,0323 & 0,0397 & 0,0132 \\
C8 & 0,0317 & 0,0403 & 0,0302 & 0,0173 \\
C9 & 0,0291 & 0,0291 & 0,0328 & 0,0218 \\
C10 & 0,0256 & 0,0285 & 0,0341 & 0,0085 \\
C11 & 0,0191 & 0,0276 & 0,0236 & 0,0236 \\
C12 & 0,0213 & 0,0232 & 0,0232 & 0,0174 \\
C13 & 0,0191 & 0,0175 & 0,0239 & 0,0143 \\
C14 & 0,0208 & 0,0134 & 0,0179 & 0,0134 \\
C15 & 0,0141 & 0,0155 & 0,0127 & 0,015 \\
C16 & 0,0134 & 0,0115 & 0,0125 & 0,01 \\
C17 & 0,0107 & 0,0099 & 0,0086 & 0,0086 \\
C18 & 0,0086 & 0,0055 & 0,0083 & 0,0055 \\
C19 & 0,0042 & 0,0046 & 0,0044 & 0,0057 \\
C20 & 0,0028 & 0,0023 & 0,0026 & 0,0023 \\
\hline
\end{tabular}

c. Menentukan himpunan Concordance dan Discordance index.

Himpunan Concordance menggunakan persamaan(3).

$\mathrm{C} 12=$

$V 11 \geq V 21=0,0519 \geq 0,0482$

$\mathrm{V} 12 \geq \mathrm{V} 22=0,0474 \geq 0,0388$

$\mathrm{V} 13 \geq \mathrm{V} 23=0,0422 \geq 0,0422$

$\mathrm{V} 14 \geq \mathrm{V} 24=0,0508 \geq 0,0469$

$V 15 \geq V 25=0,0349 \geq 0,0465 V 16 \geq V 26=0,0409 \geq 0,0275$

$V 17 \geq V 27=0,0412 \geq 0,0323$

$V 18 \geq V 28=0,0317 \geq 0,0403$

$V 19 \geq V 29=0,0291 \geq 0,0291$

$V 110 \geq V 210=0,0256 \geq 0,0285$

Dan seterusnya hingga C43 sehingga didapatkan himpunan Concordance nya. Himpunan Discordance menggunakan persamaan(4) sebagai berikut :

D12=

$V 11<V 21=0,0591<0,0482$

$V 12<V 22=0,0474<0,0388$

$V 13<V 23=0,0422<0,0422$

$V 14<V 24=0,0508<0,0469$

$V 15<V 25=0,0349<0,0464$

$V 16<V 26=0,0428<0,0275$

$V 17<V 27=0,0419<0,0323$

$V 18<V 28=0,0317<0,0403$

$V 19<V 29=0,0291<0,0291$

$V 110<V 210=0,0256<0,0285$

Dan seterusnya hingga D43 sehingga didapat himpunan Discordancenya.

d. Hitung matriks Concordancedan Discordance.

Menghitung Concordance, menggunakan persamaan(5), sebagai berikut :

$$
\begin{aligned}
C_{k l} & =w 1+w 2+w 3+w 4+w 6+w 7+w 9+w 13+w 14+w 16+w 17+w 18+w 20 \\
& =0,0950+0,0900+0,0860+0,0810+0,0710+0,0570+0,0380+0,0330+0,0240 \\
& +0,0190+0,0140+0,0050 \\
= & 0,6810
\end{aligned}
$$

dan seterusnya hingga $C 43$. Nilai dari komponen matriks disusun berdasarkan himpunan Concordancedengan bobot (W) dan dijumlahkan, sehingga menghasilkan matriks Concordance sebagai berikut :

Tabel 4. Matriks Concordance

\begin{tabular}{ccccc}
\hline Concordance & C1 & C2 & C3 & C4 \\
\hline C1 & - & 0,6810 & 0,5760 & 0,9143
\end{tabular}




$\begin{array}{lllcc}\text { C2 } & 0,4619 & - & 0,4619 & 0,8952 \\ \text { C3 } & 0,5000 & 0,581 & - & 0,8667 \\ \text { C4 } & 0,1619 & 0,2286 & 0,2762 & -\end{array}$

Menghitung Discordance., Untuk menghitung nilai dari elemen pada matriks Discordance adalah dengan membagi maksimum selisih nilai kriteria yang termasuk dalam subsetDiscordancedengan maksimum selisih nilai seluruh kriteria yang ada, secara matematisnya seperti pada persamaan(6), sebagai berikut :

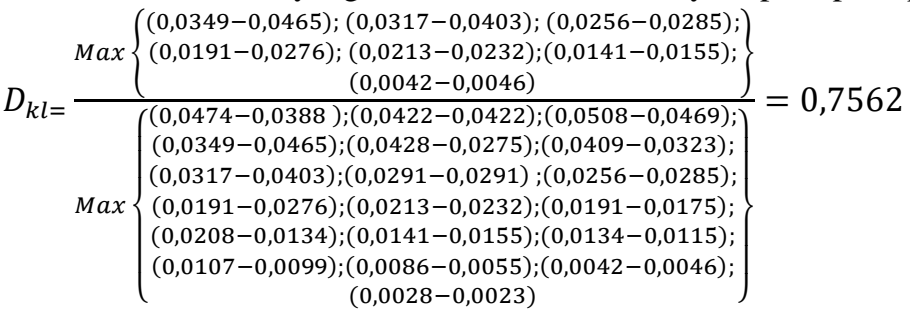

Dan seterusnya sampai D43, Sehingga diperoleh matriks Discordance sebagai berikut:

Tabel 5.Matriks Discordance

\begin{tabular}{ccccc}
\hline Discordance & D1 & D2 & D3 & D4 \\
\hline D1 & - & 0,7562 & 1,0000 & 0,1137 \\
D2 & 1,0000 & - & 1,0000 & 0,0714 \\
D3 & 0,901 & 0,4505 & - & 0,2143 \\
D4 & 1,0000 & 1,0000 & 1,0000 & - \\
\hline
\end{tabular}

e. Menentukan matriks dominan Concordancedan Discordance.

Matriks dominan Concordance, Menghitung matriks dominan ConcordanceThreshold didapat dari penjumlahan seluruh elemen matriks dibagi ukuran matriks yang terdapat pada persamaan(8) dan nilai setiap elemen matriks f sebagai matriks dominan Concordance ditentukan menggunakan persamaan(9) Sehingga matriks dominannya adalah :

Tabel 6. Matriks Concordance

\begin{tabular}{ccccc}
\hline Dominan Concordance & C1 & C2 & C3 & C4 \\
\hline C1 & - & 1 & 1 & 1 \\
C2 & 0 & - & 0 & 1 \\
C3 & 0 & 1 & - & 1 \\
C4 & 0 & 0 & 0 & - \\
\hline
\end{tabular}

Matriks dominan Discordance, Menghitung matriks dominan DiscordanceThreshold didapat dari penjumlahan seluruh elemen matriks dibagi ukuran matriks yang terdapat pada persamaan(10) dan nilai setiap elemen untuk matriks g sebagai matriks dominan Discordance ditentukan menggunakan persamaan(11).Sehingga matriks dominannya adalah:

Tabel 7. Matriks Dominan Discordance

\begin{tabular}{ccccc}
\hline Dominan Discordance & D1 & D2 & D3 & D4 \\
\hline D1 & - & 1 & 1 & 0 \\
D2 & 1 & - & 1 & 0 \\
D3 & 1 & 0 & - & 0 \\
D4 & 1 & 1 & 1 & - \\
\hline
\end{tabular}

f. Menghitung indeks Concordance murni dan Discordance murni.

Concordance murni, untuk mencari nilai Concordance murni dapat dilihat pada persamaan(12) berikut :

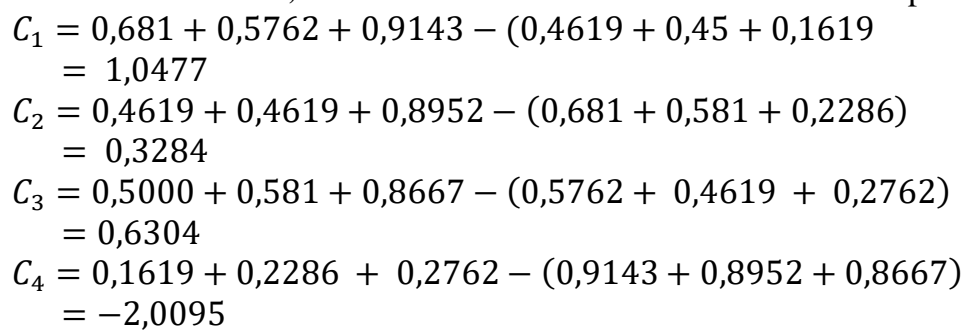

Discordance murni, Untuk mencari nilai Discordance murni dapat dilihat pada persamaan(13).

$D_{1}=0,7562+1,0000+0,1137-(1,0000+0,901+1,0000)$

$=-1,0311$

$D_{2}=1,0000+1,0000+0,0714-(0,7562+0,4505+1,0000)$

$=-0,135$

$D_{3}=0,901+0,4505+0,2143-(1,0000+1,0000+1,0000)$ 


$$
\begin{aligned}
& =-1,4342 \\
D_{4} & =1,0000+1,0000+1,0000-(0,1137+0,0714+0,2143) \\
& =2,6006
\end{aligned}
$$

Setelah kedua indeks telah dihitung, maka untuk mendapatkan alternatif terbaik adalah dengan mencari nilai rata rata dari kedua peringkat indeks Concordance murni dan Discordance murni. sehingga didapatkan peringkat peringkat sebagai berikut berdasarkan tabel 8 .

Tabel 8.Perhitungan Alternatif Terbaik

\begin{tabular}{ccccccc}
\hline Faktor & Concordance & Rangking & Discordance & Rangking & Average Rank & Final Rank \\
\hline A3 & 0,6304 & 2 & $-1,4342$ & 4 & 3 & 1 \\
A2 & 0,3285 & 3 & $-0,1350$ & 2 & 2,5 & 2 \\
A4 & $-2,0095$ & 4 & 2,6006 & 1 & 2,5 & 3 \\
A1 & 1,0477 & 1 & $-1,0311$ & 3 & 2 & 4 \\
\hline
\end{tabular}

Berdasarkan tabel 8 diatas dapat diambil keputusan bahwa A4 menjadi faktor penghambat siswa sulit berkonsentrasi pada mata pelajaran dimana alternatif A3 adalah Teman dengan average terbesar yaitu 3. Berikut adalah hasil perhitungan menggunakan program VB.NET dengan metode Electre II.

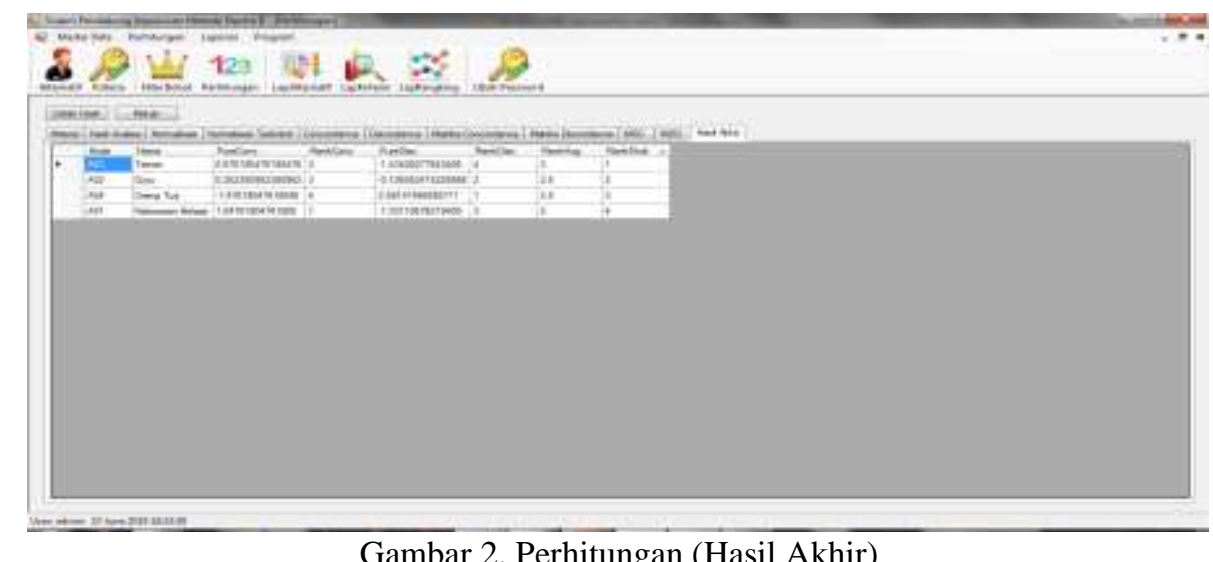

Berdasarkan hasil perhitungan dari program VB.NET dalam penentuan faktor hambatan siswa sulit berkonsentrasi dalam mata pelajaran di MAs Al- Washliyah 26 menggunakan metode Electre II baik secara perhitungan manual maupun secara komputerisasi menunjukan hasil yang sama,yaitu alternatif A03 merupakan alternatif terbaik.

\section{KESIMPULAN}

Berdasarkan hasil dari penelitian ini, dapat disimpulkan beberapa hal mengenai Penerapan Metode Electre II Dalam Menentukan Faktor Hambatan Siswa Sulit Berkonsentrasi Dalam Mata Pelajaranyaitu dengan cara merankingkan nilai Concordance dan Discordance murni dan mencari nilai average tertinggi dari keduanya. Hasil akhir yang didapat yaitu A03 dengan alternatif teman dengan nilai average terbesar yaitu 3.

\section{REFERENCES}

[1] L. P. Purba, A. P. Windarto, And A. Wanto, Faktor Terbesar Rendahnya Minat Ber-Kb ( Keluarga Berencana ) Dengan Metode Electre II, Pp. 369-374, 2018.

[2] H. J. Damanik, I. Parlina, H. S. Tambunan, And E. Irawan, Sistem Pendukung Keputusan Dalam Seleksi Penyiar Radio Boss Fm 102.8 Pematang Siantar Menggunakan Metode Electre, Komik (Konferensi Nas. Teknol. Inf. Dan Komputer), Vol. I, Pp. 38-44, 2017.

[3] K. Fatmawati, A. P. Windarto, And M. R. Lubis, Analisa Spk Dengan Metode Ahp Dalam Menentukan Faktor Konsumen Dalam Melakukan Kredit Barang, Vol. I, Pp. 314-321, 2017.

[4] T. Imandasari, A. P. Windarto, And D. Hartama, Analisis Metode Maut Pada Pemilihan Deodorant, Pp. 736-739, 2019.

[5] R. T. A. Agus And W. Sulastri, Penentuan Benih Padi Terbaik Untuk Meningkatkan Hasil Panen Menggunakan Metode Fuzzy Multi Criteria Decision Making, J. Mat. Penusa, Vol. 22, No. 1, Pp. 23-28, 2018.

[6] T. Imandasari And A. P. Windarto, Sistem Pendukung Keputusan Dalam Merekomendasikan Unit Terbaik Di Pdam Tirta Lihou Menggunakan Metode Promethee, J. Teknol. Dan Sist. Komput., Vol. 5, No. 4, P. 159, 2017. 